\title{
REFORMA DO ESTADO: O PRIVADO CONTRA O PÚBLICO
}

\author{
THE REFORM OF THE STATE: THE PRIVATE VERSUS THE PUBLIC
}

Roberto Leher 1

Resumo A reforma do Estado está situada no centro da agenda dos países periféricos, obedece às condicionalidades do Fundo Monetário Internacional (FMI) e do Banco Mundial, assim como está presente nas políticas que ampliam a esfera privada em detrimento da pública. O determinismo tecnológico - expresso por meio da ideologia da globalização - e o uso de um léxico em que o discurso da direita e da esquerda parecem se confundir - como nos temas da autonomia, da sociedade civil e da crítica ao estatismo - contribuem para a formação da ideologia dominante. Critica-se, aqui, o discurso que confere inexorabilidade a essas reformas, sustenta a ruptura com a política macroeconômica neoliberal para que a transição pós-neoliberal possa ser concretizada e defende a oposição entre o público e o privado como estratégica para a construção de alternativas. Argumenta-se que as reformas aprofundam a condição capitalista dependente do país e ampliam a sua heteronomia cultural, agravando o apartheid educacional e científico-tecnológico, com graves conseqüências sociais. Discute-se, ainda, que a construção de um Estado ético, público, requer o fortalecimento dos movimentos sociais, a autonomia vis-à-vis aos governos e a elaboração de teorias críticas em relação ao Estado, em uma sociedade não subjugada à ordem do capital.

Palavras-chave Estado; público; privado; ideologia; educação.
Abstract The reform of the State is at the centre of the periphery countries' agenda; it fulfils the conditions imposed by the International Monetary Fund and by the World Bank, as well as being part of the policies that aim at expanding the private sphere in detriment of the public one. Technological determinism - expressed by the globalisation ideology - and the use of a vocabulary that makes the discourses of both left and right seem very similar (as it occurs in the case of matters such as autonomy, civil society and the critique of statism) contribute towards the construction of the dominant ideology. Here we make a critique of the discourse that makes these reforms seem inexorable, support the rupture with the neo-liberal macroeconomic policies in order to guarantee the concretisation of the post neo-liberal transition and defend the opposition between the public and the private as a strategy for the construction of alternatives. We argue that the reforms will strengthen the dependent capitalist condition of this country and, widening its cultural heteronomy, will further intensify the existing educational and technological-scientific apartheid, with serious social consequences. We also suggest that the construction of an ethical and public State demands the strengthening of social movements, their autonomy vis-à-vis governments and the elaboration of critical theories related to the State in a society that is not subdued to the order of Capital. Key words State; public; private; ideology; education. 


\section{Introdução}

A constatação de que a perda de legitimidade das políticas neoliberais está configurando um mundo pós-neoliberal neokeynesiano, edificado sem rupturas com as políticas macroeconômicas vigentes, está assentada na crença de um novo ciclo longo de expansão na economia-mundo capaz de assegurar um forte crescimento do investimento direto estrangeiro (IDE) nas periferias.

A profunda crise de legitimidade do Consenso de Washington, expressa pelo crescimento das desigualdades, do desemprego, da pobreza, da violência e da incerteza quanto ao futuro, agravada pelo crescimento econômico medíocre das duas últimas décadas, de fato corroborou a tese de que essas políticas não têm sido capazes de oferecer alternativas à barbárie. Assim, a primeira parte da assertiva (perda de legitimidade) é consistente. Mas isso não significa que alternativas neokeynesianas estejam dadas. Em outros termos, a segunda parte da proposição tem de ser problematizada: o ciclo expansionista e o caráter virtuoso dos investimentos diretos estrangeiros como fundamentos para o revigoramento da economia, sem produzir descontinuidade com as políticas neoliberais ditadas pelo FMI, pelo Banco Mundial e pela Organização Mundial do Comércio (OMC).

Este estudo sustenta as hipóteses de que o capital em crise estrutural não demonstra disposição de abandonar o receituário neoliberal; de que após a dissipação das ilusões provocadas pela bolha de crescimento das bolsas de alta tecnologia nos Estados Unidos, não é possível vislumbrar o nascimento de um ciclo expansionista; de que os IDE não fortaleceram o setor produtivo e, desse modo, não contribuíram para a distribuição da riqueza socialmente produzida nos países periféricos. Se essas hipóteses são válidas, o Estado brasileiro continuará sendo redesenhado pelo Consenso de Washington.

Nada mais longe da verdade do que a afirmação de que as políticas pósneoliberais já estão germinando em solo fértil, inclusive no terreno das ideologias. A despeito das recentes vitórias eleitorais de Luís Inácio Lula da Silva no Brasil e de Gutierrez no Equador, da radicalização da "revolução" bolivariana de Chaves na Venezuela e da existência de governos social-democratas na Europa, a supremacia neoliberal ainda é uma realidade. Em recente conferência no Brasil2, Perry Anderson afirmou que atualmente a quase totalidade dos países - independentemente da filiação à social-democracia, ao socialismo ou mesmo ao comunismo, como a China - pratica políticas de corte neoliberal. As reformas do Estado em curso em toda parte prosseguem no trilho do pensamento único, sem grandes alterações.

Temas como autonomia do Banco Central (metas de inflação, superávit primário e elevação da taxa de juros), previdência social por regime de ca- 
pitalização através de fundos de pensão, políticas sociais encaminhadas a partir de ONGs, voluntariado e outras modalidades não-estatais, bem como a focalização da ação do Estado dirigida ao "aliviamento" da pobreza, com vistas à governabilidade, seguem em inédito aprofundamento.

Mais amplamente, a liberalização dos mercados dos países capitalistas dependentes, a flexibilização dos direitos sociais e "o 'cumprimento das promessas' feitas apenas aos interesses mais arraigados do capital, seja no domínio do capital financeiro (...) ou em alguns de seus setores industriais ou quase monopolistas" (Mészáros, 2003, p. 97) movem-se, ainda, como uma gigantesca onda que arrasa cidades, países e vastas regiões do globo.

Quanto ao novo ciclo expansionista, capaz de fazer renascer o neokeynesianismo, Brenner (2003), mediante estudo da bolha de crescimento da economia dos Estados Unidos na década de 1990 e da evolução das ações das corporações da chamada "nova economia", oferece consistentes argumentos de que é uma aposta desprovida de fundamentação séria, análise que conta com a concordância de Mészáros (2003, p. 97):

“(...) dada a crise estrutural do sistema do capital, mesmo que uma alteração conjuntural fosse capaz de criar durante algum tempo uma tentativa de instituir alguma forma de administração financeira keynesiana do Estado, ela teria forçosamente uma duração muito limitada devido à ausência das condições materiais que poderiam favorecer sua extensão por um período maior, mesmo nos países capitalistas avançados" (Mészáros, 2003, p. 97).

Finalmente, a crença de que os investimentos diretos estrangeiros (IDE) poderiam alavancar as economias periféricas foi vigorosamente contestada por Chesnais (1996), Arrighi (1997) e, no caso brasileiro, por recente estudo do Instituto de Estudos para o Desenvolvimento Industrial (IEDI) (Nassif, 2003). O montante de recursos externos aportados no Brasil entre 1996 e 2001 foi, de fato, muito significativo: US\$ 125 bilhões. No entanto, conforme o estudo, o maior legado foi o agravamento do desequilíbrio externo do país. O IDE se dirigiu a setores industriais deficitários em sua balança comercial ou com baixo volume de comércio exterior, acarretando aumento nos gastos com juros, remessas de lucros e pagamento de royalties às matrizes.

Assim, as próprias empresas estrangeiras se converteram nas grandes responsáveis pelo déficit em transações correntes (1995 = 31,8\% do déficit; $2000=61 \%$ do déficit). Também as corporações estrangeiras foram as maiores responsáveis pelo crescimento da dívida externa brasileira, que passou de US\$ 159 bilhões, em 1995, para US\$ 236 bilhões, ao final de 2000 (aumento de US\$ 77 bilhões). Vale destacar que as empresas estrangeiras foram responsáveis por $67 \%$ desse crescimento. 
Ainda que as hipóteses destacadas anteriormente tenham sido examinadas de forma sucinta, pode-se afirmar que os pretensos fundamentos de uma nova arrancada para o desenvolvimento são pouco consistentes. De um lado, os movimentos antineoliberais estão mais mundializados e, cada vez mais, incidem suas ações diretamente contra os "senhores do mundo", como o Banco Mundial, o FMI, a OMC e a Área de Livre Comércio das Américas (AlCA) e, notavelmente, contra o imperialismo dos Estados Unidos, particularmente na ação genocida contra o Iraque. O III Fórum Social Mundial e a realização da maior manifestação da História contra a guerra, na qual manifestantes de 60 países promoveram atos simultâneos em 15 de fevereiro de 2003, reunindo milhões de pessoas, são sinais alentadores de que a resistência ganha densidade e assume caráter de massa.

Por outro lado, os Estados Unidos têm adotado a estratégia da "guerra infinita" (Ceceña e Sader, 2002): diante de qualquer gesto de soberania, logo a lista do "eixo do mal" é acrescida de um nome, com todas as conseqüências daí advindas.

Assim, contrariando expectativas ufanistas ou o discurso neoliberal dissimulado, a reforma do Estado é de aguda atualidade. O capitalismo não pode prescindir do Estado, pois, em virtude de sua crise estrutural, novos meios de subordinação do trabalho ao capital serão postos em marcha, sem falar no pagamento do tributo neocolonial da dívida, na flexibilização dos direitos sociais e na liberalização das movimentações financeiras.

A necessidade que o capital tem do Estado é crescente, não apenas para facilitar o planejamento capitalista, assumir riscos ou para manejar ou conter conflitos de classes, como também para levar a cabo as funções sociais abandonadas pela classe apropriadora e minorar os seus efeitos anti-sociais. Com isso, o Estado social deverá prosseguir encolhendo, cúmplice do capital em seus propósitos anti-sociais, em detrimento do bem público.

As instituições de pesquisa, as universidades, as escolas e os hospitais ainda estão enquadrados na moldura neoliberal e somente por meio de análise teórica rigorosa articulada à ação política organizada dos movimentos sociais será possível vislumbrar uma refundação do Estado como esfera pública. É, portanto, uma história em aberto.

O primeiro grande desafio teórico consiste em desconstruir o discurso que pretende legitimar as reformas neoliberais com "face humana" nos moldes da Terceira Via de Giddens/Blair. Trata-se de uma tarefa difícil, já que temas axiais como 'descentralização', 'autonomia', 'interação com a comunidade' fazem borrar as análises da direita e da esquerda.

É preciso diferenciar as motivações que levaram setores da esquerda a criticar o Estado capitalista, advogando sua reconfiguração em bases radicalmente democráticas, em especial nas jornadas de 1968, das manifestações de Hayek, Friedman, Tullock etc., quando se lançaram na luta pelo Estado 
dito mínimo e pela supremacia do mercado. Mesmo após mais de duas décadas de hegemonia neoliberal, conceitos e noções aparecem embaralhados, sobrepostos, mitigados, turvando as condições de análise do real, em proveito do capital.

\section{Reforma do Estado: do espírito de 68 às reformas neoliberais}

Somente um projeto de investigação específico - e de grande envergadura - poderia se propor a examinar as diversas leituras acerca do Estado empreendidas pelos movimentos, correntes de pensamento e intelectuais que participaram dos movimentos de 1968 na Europa. Dos Partidos Comunistas aos ecologistas, a diversidade de enfoques é imensa. Os objetivos desta seção são evidentemente muito mais modestos: oferecer indicações que corroborem a proposição de que parte da crítica ao Estado, realizada por setores da esquerda, possui pontos de convergência com as teses liberais, conforme sugerem Jean-Pierre Dupuy (1983) e Boltanski e Chiapello (1999).

Complementarmente, também interessa sugerir que a crítica ao Estado como aparelho ideológico contribuiu para debilitar a crença na possibilidade de ampliação do espaço público das políticas de bem-estar social através das lutas de classes, enfraquecendo a resistência ao desmonte do Estado social.

Os bem marcados traços estalinistas do socialismo soviético e dos países do (mal denominado) "socialismo real" desenharam um Estado que, muito justamente, deixou de ser referência para os movimentos socialistas, organizados em sindicatos, partidos e em movimentos de mulheres, ambientais e estudantis. Em confronto com o modelo soviético, Castoriadis (1983) defendeu a autonomia como um valor a ser perseguido e condição para o autogoverno e a autogestão. Essas idéias ganharam repercussão e sentido nas jornadas de 1968. A sociedade industrial foi denunciada por sufocar a criatividade, a capacidade de iniciativa, bem como por adotar padrões uniformes associados ao consumismo.

Essas críticas logo alcançaram o Estado. As instituições escolares foram criticadas como uniformizadoras, cerceadoras da criatividade e reprodutoras das desigualdades sociais. Bandeiras dos libertários como emancipação e livre associação entre criadores motivados por uma mesma paixão postulavam o desejo de ultrapassar o capitalismo e também o anticapitalismo (soviético/leste europeu).

A crítica à planificação não se restringia à uniformização do trabalho ou da educação. Para ecologistas, autonomistas e libertários era preciso combater o enquadramento do Estado pelo capitalismo. Mas a crítica resvalou para um anti-estatismo abstrato, idealizado, incapaz de captar as complexas imbricações Estado-capital-luta de classes. O Estado de bem-estar foi vigorosa- 
mente criticado em nome de formas alternativas de associação não-estatal, como as escolas comunitárias autogeridas.

Em Althusser, a distinção Estado-sociedade civil é abolida, resultando na tese segundo a qual igrejas, partidos, sindicatos, famílias, escolas e jornais constituem "os aparelhos ideológicos do Estado", colocando um fim nas fronteiras entre público e privado:

“Não é importante saber se as instituições nas quais elas (as ideologias) se realizam são públicas ou privadas - pois estas constituem indiferentemente setores de um único Estado, que as controla e que é a precondição para a distinção entre público e privado" (Althusser, apud Anderson, 2002, p. 51).

Contudo, assinala Anderson (op. cit., p. 52):

“(...) as fronteiras do Estado não constituem um tema indiferente para a teoria marxiana ou para a prática revolucionária. É essencial poder defini-las com precisão. Deixá-las fluídas é, na verdade, não compreender o papel específico e a eficácia das superestruturas exteriores ao Estado na democracia burguesa" (Anderson, op. cit., p. 52).

Através da distinção entre a democracia parlamentar e o fascismo (neste, de fato, não existe distinção entre Estado e sociedade civil), Gramsci sustenta que há fortes diferenças entre Estado e sociedade civil. Como bem observou Anderson a respeito de Gramsci:

“(...) com os acontecimentos de 1924-26, quando todos os partidos políticos foram suprimidos, ele escreveu, a coincidência do país real e do país legal foi doravante proclamada na Itália, porque a sociedade civil em todas as suas formas estava agora integrada a uma organização político-partidária do Estado" (Anderson, op. cit., p. 54).

Nos Cadernos, outra passagem atesta que é sob o fascismo que ocorre a indiferenciação sustentada por Althusser:

“As ditaduras contemporâneas juridicamente aboliram até as formas modernas de autonomia das classes dominadas - como os partidos, os sindicatos, as associações culturais - e assim procuram incorporá-las à atividade do Estado: a centralização legal de toda a vida nacional nas mãos do grupo dominante, que é agora totalitário" (Quaderni del Carcere, III, p. 2287, apud Anderson, op. cit., p. 55).

As proposições de Althusser contribuíram para deslocar a análise do Estado nas democracias burguesas ocidentais, assim como as reflexões so- 
bre a forma como as lutas de classes operavam em seus aparelhos de hegemonia. Visto de forma unilateral, como pólo negativo, o Estado-aparelho ideológico deixou de ser um objeto de estudo decisivo para o estabelecimento das estratégias políticas da classe-que-vive-do-trabalho. As conseqüências, como a história recente pode atestar, foram o enfraquecimento de direitos sociais conquistados a suor e sangue, assegurando o avanço sem precedentes do privado sobre o público, do interesse individual sobre o coletivo, da desigualdade sobre a igualdade.

Um quarto de século mais tarde, a força da crítica ao Estado já era suficiente para defender a tese do fim do Estado-nação (Ohmae, 1999). Com efeito, segundo a formulação ideológica em vigor, a globalização teria dissolvido muitas fronteiras e barreiras, fazendo emergir o mercado mundial ou globalizado. É importante lembrar que segmentos importantes da esquerda, como a reunida em Le Monde Diplomatique, confirmavam que, em virtude de uma chamada "revolução científico-tecnológica", o mundo estava, de fato, se globalizando (e, portanto, os Estados-nação estavam se desvanecendo), em detrimento dos direitos sociais da classe-que-vive-do-trabalho e em favor do capital rentista. A propósito da cruzada anti-estatal, a síntese de Borón (2003) é cortante:

“(...) por mais que alguns teóricos falem da 'desestatização' ou da descentração do estado, este continuará sendo, por bastante tempo, um componente fundamental de qualquer sociedade de classes. É melhor contar com diagnósticos precisos sobre sua estrutura e funcionamento e com estratégias adequadas para enfrentá-lo, pois a realidade do poder não se dissolve no ar diáfano da manhã graças a uma evocação apaixonada das bondades do 'antipoder' ou do 'contrapoder' (...)".

\section{Estado mínimo e a supremacia do Mercado: a retórica neoliberal}

As análises neoliberais do Estado se fundamentam nos pressupostos neoclássicos sob a sua forma mais ortodoxa. Sustentam que, diferente do Estado, o mercado é fruto de um lento processo de depuração por meio da evolução natural das relações entre os homens em permanente luta pela liberdade. Hayek (apud Anderson, 2002), por exemplo, estabeleceu a distinção entre duas linhagens do liberalismo, de origens radicalmente opostas.

A primeira era uma linha empiricista, vinculada essencialmente à tradição britânica que descendia de Hume, Smith e Ferguson, que viam o desenvolvimento político como um processo involuntário de aprimoramento institucional gradual, comparável ao funcionamento da economia de mercado ou à evolução do direito (cosmos) (Anderson, 2002, p. 331), linha à qual se 
filia Locke. A segunda linhagem era racionalista, tipicamente francesa, descendente de Descartes, passando por Condorcet e chegando até Comte, que consideravam as instituições sociais como sujeitas à construção premeditada, dentro do espírito da engenharia politécnica (taxis). Apenas a primeira conduzia à verdadeira liberdade, a segunda a destruiria.

Hayek conclui que a extensão do Estado é a causa exclusiva das dificuldades das sociedades contemporâneas. A crise não é da economia de mercado e do capitalismo, mas do Estado e das instituições públicas. De acordo com esse pensamento, a ação do Estado na economia é desestabilizadora e perturba o mercado, pois o serviço público é ineficiente e produz restrições deformantes. No regime democrático, as instituições públicas hipertrofiam o Estado, requerendo mais impostos e acarretando elevação dos custos da produção/circulação, perda de dinamismo econômico, desemprego e mais gastos públicos (seguro-desemprego etc.).

Em resumo, as políticas públicas levam a um ciclo vicioso que teria de ser quebrado para que o crescimento econômico pudesse fluir sem obstáculos. Nesse sentido, “observou Hayek, um regime autoritário que reprimisse o sufrágio popular, mas respeitasse o domínio do direito, poderia ser melhor guardião da liberdade do que um regime democrático sujeito às tentações de intervenção econômica ou de distribuição social" (Anderson, 2002, p. 332).

Para evitar a permanente erosão da divisão entre cosmos e taxis - imbricação típica do Estado de bem-estar social - seria necessário uma reforma drástica da estrutura do Estado. Como assinala Perry Anderson, Hayek propôs a extinção de todas as legislaturas conhecidas para formar dois novos corpos com diferentes competências e eleitorados, que corresponderiam às duas espécies ontológicas de ordem: uma câmara, com maiores poderes, guardiã do domínio do direito em si, de cujo eleitorado não poderia participar nenhuma pessoa com menos de 45 anos (seria o preço a pagar contra a soberania popular); e uma assembléia mais ampla, mas desprovida de poderes efetivos. Assim, o limite do governo dar-se-ia pelo rigor da lei e não pela licença da maioria.

Um dos mais célebres discípulos da escola neoliberal, Milton Friedman, assevera que as políticas econômicas do Estado são incorrigivelmente inflacionárias. O exemplo mais contundente dessa tendência é a política de pleno emprego que insiste em querer negar a taxa natural de desemprego, condição para o equilíbrio de mercado. De especial importância para este estudo é a tese da escola conhecida como Public Choice, que defende o exame dos mecanismos endógenos subjacentes às políticas de Estado.

Esta escola sustenta que as intervenções públicas produzem uma "burocracia" que utiliza as verbas públicas de forma menos eficaz do que o mercado. Nunca existe um controle pleno dos cidadãos sobre os burocratas, os 
quais, por isso, gastam mais do que o necessário, visto que faz parte do burocratismo a maximização de seus orçamentos. Também fazem parte alianças com os grupos de pressão, por meio de práticas clientelistas.

Já as ações dos políticos, burocratas e eleitores são análogas às das firmas do mercado. Enquanto estas maximizam a busca de lucros, aqueles maximizam a busca de votos; as firmas desejam consumidores, os políticos, eleitores. Em retribuição aos votos, a classe política promete verbas para os distritos eleitorais e a ampliação dos serviços públicos. Similarmente, os burocratas buscam aumentar seus salários e o orçamento de seu setor. Para que esse encadeamento funcione, mais impostos são necessários, rebaixando a taxa de lucros e, portanto, a capacidade de investimentos, gerando o ciclo vicioso já mencionado.

A escola Public Choice chega a uma conclusão perturbadora: o funcionamento do sistema democrático tende a dar mais poder aos interesses particularistas que aos contribuintes. O jogo democrático acarreta o crescimento (indesejável) do Estado e, por conseguinte, não se coaduna com o livre mercado. Como compete às políticas neoliberais romper com esse ciclo vicioso, a privatização é defendida como medida capaz de reduzir os gastos estatais e, ao mesmo tempo, a dívida pública, pelo ingresso da receita das privatizações.

Para escapar das "armadilhas da democracia", os governos afinados com esse pensamento promovem uma radical reforma do Estado, de forma que o interesse privado suplante o público. O locus de decisões fundamentais (câmbio, juros, inflação, preços outrora administrados pelo Estado etc.) é deslocado para espaços extra-estatais ou, se não for possível, para esferas em que o poder legitimado pelo voto popular não tenha maior poder de interferência. Este é o sentido do recente debate acerca da autonomia do Banco Central e das Agências Reguladoras. Os governos mudariam, mas não o coração das políticas econômicas.

A mesma motivação está na base da criação de conselhos da sociedade civil (via de regra hiper-representada pelo capital e pelas ONGs) para "assessorar" as políticas públicas. Aparentemente, tudo é muito democrático, mas o simples exame de sua composição, forma de escolha e de suas atribuições comprova que são loci em que "consensos" podem ser falsificados, em que "maiorias silenciosas" são evocadas para excluir ou reprimir movimentos ou idéias dissidentes.

É desconcertante que, em nome de um pacto social entre o capital e o trabalho, o governo de Luís Inácio Lula da Silva tenha optado por criar um Conselho de Desenvolvimento Econômico e Social (Codes) de clara inspiração neocorporativista, vinculado à Presidência da República. Pelo menos duas ordens de questões são necessárias para compreender o significado do referido Conselho. 
A primeira diz respeito à forma. A tradição operária reivindica os "conselhos" como forma de auto-organização dos trabalhadores em seu local de trabalho, podendo ou não ter duração limitada, com o objetivo de controlar suas condições de produção e a construção de um outro Estado, o Estado operário. Mais amplamente, na experiência da revolução de 1917, foram denominados de 'sovietes'; e na experiência de Turim (anos 20), relatada por Gramsci, agrupavam o conjunto da classe (sistema de conselhos) e não categorias específicas, como os sindicatos, e tinham objetivos semelhantes aos dos 'sovietes': o socialismo.

Em comum, todas essas experiências têm como pressuposto fundamental a autonomia e a auto-organização da classe-que-vive-do-trabalho. Somente por uma usurpação semântica, o Codes poderia ter alguma proximidade com a tradição da esquerda. Ao contrário, é um órgão vinculado ao governo federal, em que todos os membros são nomeados pelo chefe do Executivo. Por isso, o “Termo de Referência" (2003), que estabelece as diretrizes de seu funcionamento, reivindica o modelo do "pacto social" espanhol (1977) e do Acordo de Concertação Estratégica de Portugal (1996/99), assumindo fins conciliatórios.

A segunda ordem de problemas está relacionada a sua composição e atribuições. É um órgão da “sociedade civil, de caráter consultivo, que relaciona o Executivo com distintas representações do empresariado, do terceiro setor, dos movimentos sociais e do mundo do trabalho" (SECOD, 2003). A composição é de livre arbítrio da Presidência da República e as posições, conforme o modelo original, são classificadas em "majoritárias" ou "consensuais" (a dissonância não está prevista, provavelmente devido à composição e à forma de nomeação dos "representantes" pelo Presidente): 41 são empresários, 13 são sindicalistas, 11 são ligados a movimentos sociais, 10 são "personalidades", três são representantes de entidades de classe, dois são da área cultural, dois são religiosos e nove são ministros.

Um exame minucioso mostra um quadro que comprova a impossibilidade de autonomia diante do governo. Diversos empresários foram grandes doadores da campanha de Lula. Entre os representantes dos trabalhadores, um deles é membro do conselho de uma estatal nomeado pelo atual governo, recebendo pró-labore de valor expressivo; três representam centrais diminutas, sem expressão no mundo do trabalho. Uma das duas representantes da área cultural trabalha para uma grande instituição bancária e, entre os representantes dos movimentos sociais, vários são do chamado terceiro setor, sendo que o Movimento dos Trabalhadores Rurais Sem-Terra (MST), o principal movimento social do país, não foi convocado. É, por conseguinte, um conselho das classes dominantes que objetiva cimentar a aliança estratégica para um novo contrato social.

Enunciada por uma retórica libertária, a crítica ao Estado nos anos 70 poderia não reconhecer a sua proximidade com o liberalismo. Contudo, sob 
diversos aspectos, era liberal sem o saber. A adesão a uma denúncia virulenta do Estado não supunha, a rigor, uma renúncia às vantagens do Estado providência. Mas era disso que o pensamento liberal estava falando. E a crítica à escola pública, por seu caráter reprodutivista, e a defesa de modalidades de educação não vinculadas ao Estado, ditas populares, acabaram por jogar água no moinho da privatização.

Faz parte desse movimento a exacerbação da gelatinosa "sociedade civil" (desprovida de classes sociais, em antípoda ao Estado) que, em meados dos anos 80 e ao longo da década de 90, passou a protagonizar políticas sociais "alternativas" ao Estado autoritário e burocrático, por meio das organizações não-governamentais, muitas delas financiadas por organismos internacionais e corporações (Leher, 2000).

Como observa Sader (2002), agentes do neoliberalismo, como o Banco Mundial, têm-se utilizado dessas organizações taticamente, em especial para implantar políticas sociais compensatórias. O caso mais característico talvez tenha sido o México, em que grande parte da política de "alívio à pobreza" foi encaminhada por ONGs que atuaram em vínculo direto com os setores dominantes, como as grandes corporações multinacionais e o próprio PRI. Recente notícia sustenta que o Presidente Fox segue o mesmo caminho para "combater" o analfabetismo 'Sahagún y Gordillo sellan alianza entre Vamos México y el SNTE' (La Jornada, 2003).

Nesses termos, temas como 'poder', 'Estado', 'esfera pública', 'lutas ideológicas', 'táticas' e 'estratégias contra o neoliberalismo' ficam fora de foco, debilitando a luta antineoliberal concreta. A alternativa para grande parte dessas organizações é "pensar globalmente, agir localmente". Não há construção hegemônica ou ações políticas capazes de potencializar as lutas dos que vivem-do-trabalho nos planos local-nacional, local-regional e localinternacional.

Os embates sobre o caráter do Fórum Social Mundial expressam esses dilemas, visto a predominância de ONGs em seu secretariado. A conexão entre essa forma de atuação e o pensamento liberal não passou despercebida por Sader (2002, p. 93): “elas (ONGs) se inserem, implícita ou explicitamente, na crítica liberal das ações do Estado", ou então limitam suas atividades à esfera da sociedade civil, que, definida em oposição ao Estado, também fica restrita aos limites das políticas liberais.

Desse modo, entre a crítica da esquerda nas jornadas de 1968, as ONGs e as proposições neoliberais, existem pontos de convergência situados nas escolhas lexicais e remetendo para além delas. Expressões como 'autonomia', 'autogoverno' e 'auto-regulação' circularam em seus discursos de forma polissêmica. Entretanto, o anti-estatismo foi um traço comum a todos eles. Embora no pensamento autonomista a ênfase esteja na crítica ao Estado e à burocracia, com vistas ao autogoverno dos trabalhadores, seu anti-esta- 
tismo é abstrato e idealizado, não engendrando lutas concretas contra as classes dominantes.

Por isso, o Estado social (a esfera pública) sai de foco. Além disso, o discurso anti-autoritário favoreceu a audiência ao neoliberalismo que, desse modo, parecia ter um certo frescor diante da pesada herança do Estado-keynesiano, que teria hipertrofiado a burocracia e a intervenção na economia. Temas como 'criatividade', 'realização individual', 'eficiência' e 'reconhecimento dos méritos individuais' soaram confortáveis para vastos setores sociais, como se fossem ecos de discursos libertários de outrora.

\section{Reforma do Estado no Brasil}

Quando Bresser Pereira afirmou, na reunião que originou a expressão “Consenso de Washington" (1989), que o país, no fundamental, estava de acordo com o decálogo de medidas consideradas desejáveis pelos Estados Unidos, certamente o fez com propriedade. As bases para a implementação da agenda neoliberal por Collor de Mello estavam sendo erigidas desde a Crise da Dívida de 1982, ainda que de forma descontínua e em ziguezague.

O Plano Cruzado havia sido uma tentativa de desvio da rota imposta pelas condicionalidades do FMI, do Banco Mundial e do Departamento de Estado dos Estados Unidos, porém, com a hiperinflação (provavelmente comemorada pelas grandes corporações e por Washington), o país - como, de resto, a América Latina - voltou ao caminho preconizado por esses organismos, em especial por meio da adoção dos programas de estabilização com âncora cambial, matrizes da desastrosa abertura financeira, da regressão industrial e da perda de dinamismo dos anos 90. No Plano Real, uma série de medidas previstas no referido "consenso" foi implementada:

“(...) abertura comercial; liberalização das contas de capital; desregulamentação e 'descompressão' dos sistemas financeiros domésticos; reforma do Estado, incluindo a privatização da seguridade social e o abandono de políticas de fomento à indústria e à agricultura" (Belluzo, 2002, p. 18).

De fato, a exemplo do que ocorreu na quase totalidade dos países periféricos, a reforma do Estado brasileiro foi, em diversos sentidos, mais ortodoxa em relação ao credo neoliberal do que a de países centrais: renunciou ao seu papel dinamizador da economia, incluindo C\&T, educação de alta qualidade, política industrial, planejamento e coordenação de ações etc. O resultado da destruição do Estado foi o aprofundamento da condição capitalista dependente (Fernandes, 1977) e o agravamento do apartheid social. 
Doravante, os mais importantes direitos republicanos - educação, saúde, previdência - deveriam ser "adquiridos" no mercado. Aos pobres, restariam as políticas caritativas e focalizadas, como, por exemplo, programas alimentares, alfabetização e treinamento. É relevante destacar que nem essas políticas são rigorosamente públicas. A chamada sociedade civil é convocada a dividir parte de sua renda e de seu tempo com o atendimento dos pobres para "aliviar" seu sofrimento e sua "ignorância" (vide alfabetização solidária e sua campanha "adote um aluno"), com o objetivo de manter as condições de governabilidade. Os impostos que deveriam custear políticas consistentes e duradouras são direcionados ao pagamento do serviço da dívida, enquanto as grandes fortunas pouco ou nada contribuem para o fundo público.

Se no início do primeiro governo FHC ainda se falava nos aspectos conceituais da reforma do Estado — do Estado burocrático ao gerencial após oito anos de governo ficou patente que a meta e o ritmo da reforma foram balizados pela redução do Estado social, com o objetivo de pagar juros advindos do crescimento exponencial dos estoques das dívidas interna e externa. Ao longo do Plano Real, a dívida cresceu 20 pontos percentuais do PIB, índice que somente teve paralelo na crise da dívida de 1982 (Carneiro, 2002).

A partir da crise de 1998, por exigência do acordo com o FMI, o país passou a buscar elevados superávits primários - o que, no contexto, somente tem sido possível com cortes nos gastos públicos. Nos marcos da política macroeconômica em vigor, os juros dificilmente poderão ser significativamente reduzidos, restando ao Estado promover cortes cada vez mais acentuados nos gastos públicos para alcançar os mencionados superávits primários ou contar com um improvável crescimento do PIB. Considerando o crescimento médio da dívida de $5 \%$ do PIB/ano e a baixa taxa de crescimento econômico (cerca de 1,5-2,0\% do PIB), o superávit primário terá de ultrapassar $4 \%$ do PIB, índice adotado pelo governo de Luís Inácio Lula da Silva. Essa é a medida que orienta, na prática, o ritmo e o conteúdo da reforma do Estado.

Embora seja um equívoco supor sua primazia, aspectos doutrinários são importantes, pois possibilitam aos governos operar a política de reforma com o menor desgaste permitido pelas circunstâncias. Entre os aspectos que justificariam a reforma do Estado, segundo Bresser Pereira (1996), dois são centrais:

a) a emergência do mundo globalizado, em virtude de uma revolução científico-tecnológica liderada pelas corporações transnacionais. Por isso, novas formas de organização dos Estados teriam de ser introduzidas;

b) a questão fiscal. A crise econômica da década de 80 se expressou, também, como crise do Estado, tida por Bresser Pereira como uma crise fiscal e, 
por esse motivo, um forte ajuste seria condição para a retomada dos investimentos. O ajuste teria de se dar por meio de contundentes cortes nos gastos públicos e não tanto pela reforma tributária, afinal não realizada por FHC.

$\mathrm{Na}$ análise de Bresser, isso não significaria prejuízo para a qualidade dos "serviços": com o moderno Estado gerencial, a eficiência dos gastos públicos seria muito maior e, desse modo, mesmo com menos recursos, a qualidade dos "serviços" até poderia ser melhorada. Como registram com propriedade Silva Jr. e Sguissardi (1999, p. 28):

“(...) a chamada modernização ou o aumento de eficiência da administração pública será, para o Ministro, resultado de um complexo projeto de reforma, que vise a um só tempo o fortalecimento da administração pública direta — núcleo estratégico do Estado - e a descentralização da administração pública com a 'implantação de agências executivas e de organizações sociais' controladas por contratos de gestão" (Silva Jr. e Sguissardi, 1999, p. 28).

Para edificar o Estado gerencial, a Constituição de 1988, que, segundo Bresser, fez o país retroceder aos anos 30, teria de ser radicalmente reformada, restringindo o Regime Jurídico Único dos servidores públicos para os setores "exclusivos de Estado". E a nova aparelhagem estatal teria de ser construída segundo os dois eixos mencionados acima: um núcleo burocrático, voltado para a consecução das funções exclusivas do Estado, e um setor de serviços sociais e de obras de infra-estrutura.

Com base nessa consideração, Bresser Pereira afina sua proposta de reforma, identificando "quatro setores no Estado: (1) o núcleo estratégico do Estado, (2) as atividades exclusivas de Estado, (3) os serviços não-exclusivos ou competitivos, (4) a produção de bens e serviços para o mercado" (Bresser Pereira, 1996). Tendo em vista os propósitos do presente artigo, interessa destacar o item (3): na União, os serviços não-exclusivos de Estado mais relevantes são as universidades, as escolas técnicas, os centros de pesquisa, os hospitais e os museus. A reforma proposta é a de transformá-los em um tipo especial de entidade não-estatal, em organizações sociais.

Como parte do processo de transformação das autarquias e fundações públicas em organizações sociais, uma série de medidas foi encaminhada para todos os setores da administração pública. Mais amplamente, o governo Cardoso promoveu uma reforma constitucional, por meio das Emendas Constitucionais nos 19 e 20, que possibilitaram um grande arcabouço para as reformas vindouras.

A primeira reforma promove mudanças que permitem a coexistência de dois regimes de trabalho no Estado: estatutário (núcleo estratégico) e CLT (serviços não-exclusivos do Estado), enquanto a segunda pretende acabar com a aposentadoria integral do servidor, em favor dos fundos de pensão 
(capitalização). Com essas grandes medidas, o caminho para a "publicização" (eufemismo para privatização) estaria pavimentado. Assim, bastaria a aprovação de legislação ordinária para criar as organizações sociais flexíveis, competitivas e afinadas com as demandas de mercado.

Concomitantemente, o Executivo avançou na "descentralização" dos serviços sociais - como a municipalização espúria do ensino fundamental por meio do Fundo de Manutenção e Desenvolvimento do Ensino Fundamental e de Valorização do Magistério (FUNDEF). Também procurou assegurar "dramática autonomia" financeira e administrativa ao setor de "serviços" não exclusivos de Estado, como universidades, escolas técnicas, hospitais, centros de pesquisa e o próprio sistema de previdência (Bresser Pereira, 1996; Silva Jr. e Sguissardi, 1999).

Foi nesse contexto que o Ministério da Educação tentou aprovar a conhecida Proposta de Emenda Constitucional no 370-A/96. Seu objetivo era conceder grave autonomia às universidades federais, de modo que, nas palavras do relator da referida proposta, Dep. Paulo Bornhausen, essas instituições pudessem "caminhar com os próprios pés" em um prazo de dez anos. O MEC e o Ministério da Administração e da Reforma do Estado chegaram a elaborar um documento conjunto com um roteiro de extinção e recriação das universidades como entes "públicos não-estatais".

Observe-se que os temas da descentralização e da autonomia são retomados pelo governo Cardoso como noções axiais da reforma do Estado. É quase possível escutar ecos de 1968, pois é evidente o diapasão de Hayek e Friedman. Cumpre destacar que essas noções estão presentes em todos os documentos sobre Educação, Ciência e Saúde do Banco Mundial elaborados na década de 1990.

Outro aspecto a sublinhar é que os setores considerados não exclusivos de Estado são definidos como "serviços" competitivos. Isso não é uma mudança menor, afinal, na mesma época, na Rodada Uruguai do Acordo Geral sobre Tarifas e Comércio (GATT), os Estados Unidos obtiveram importante vitória ao conseguirem incluir os "serviços" nos tratados de livre comércio. O avanço das corporações em temas como propriedade intelectual e liberalização dos "serviços" educacionais, das compras governamentais etc. motivou, anos mais tarde, as grandes manifestações populares em Seattle e Gênova. As políticas de FHC podem - e devem - ser criticadas por seu caráter antinacional e antipopular, mas nunca por falta de organicidade com a política do centro hegemônico.

Os trabalhadores de diversos setores do serviço público rejeitaram essa política, em especial os das universidades, da Previdência, da Receita Federal, dos centros de pesquisa, entre outros. Na ausência de diálogo e em virtude de medidas repressivas, uma série de greves foi deflagrada no período, interpondo resistência às reformas. O ex-Presidente da República conseguiu 
modificar a Constituição em pontos importantes, no entanto, não obteve êxito na operacionalização de todas as reformas que planejou, em especial não logrou transformar o regime de trabalho nas universidades. Também a reforma da previdência no setor público permaneceu inconclusa, ainda que constasse do acordo com o FMI de 1998.

Com o objetivo de examinar os fundamentos do discurso pretensamente legitimador dessas reformas, é preciso discutir, brevemente, a pretensão de validade dos mesmos. De especial interesse para este artigo é verificar se, de fato, os Estados hegemônicos seguem a mesma linha de reformas que as preconizadas pelas instituições do Consenso de Washington. Examinando conexões dos Estados (G-7) com corporações, organismos internacionais, nova economia e gastos públicos gerais, o estudo propõe que esses Estados estão longe de ter perdido centralidade no capitalismo de hoje e que suas políticas, ao contrário da propaganda dos apologetas da globalização, estão fortalecendo a capacidade de intervenção em setores estratégicos (regras comerciais, movimentação financeira, tecnologia, energia e matérias-primas).

Sobressai uma preocupação de fundo: a crescente assimetria entre os países centrais (em particular os Estados Unidos) e os periféricos (como o Programa das Nações Unidas para o Desenvolvimento tem demonstrado). O G-7 e os organismos internacionais a ele vinculados têm promovido políticas que agravam a condição capitalista dependente dos países periféricos, convertidos, dramaticamente, em países fornecedores de commodities, mãode-obra barata (maquilas), energia de baixo custo (a transferência das indústrias de alumínio do centro para a periferia é um exemplo contundente) e em mercado pequeno, mas atraente, devido à extraordinária concentração de renda dos mesmos.

\section{Ideologia do fim do Estado nos países centrais}

Supostas provas empíricas são evocadas para metamorfosear a ideologia da globalização em um conceito científico. Entre as mais recorrentes, destacamse: a emergência de empresas transnacionais; a supremacia dos organismos internacionais em relação aos Estados nacionais; a revolução tecnológica, em especial das comunicações, que estaria jogando por terra as antigas barreiras entre as nações; e a circulação inédita de capitais, mercadorias e trabalho. Como em Limoeiro-Cardoso (1999), a análise aqui desenvolvida sustenta, distintamente, que a globalização não é um conceito científico, mas uma ideologia.

"As corporações globais não têm mais um centro nacional, agora são transnacionais dispersas pelo globo": é verdade que as corporações possuem mobilidade jamais vista e, de fato, fragmentaram a produção de com- 
ponentes. Contudo, não deixaram de possuir um "quartel-general", local em que as decisões estratégicas são tomadas por um núcleo dirigente, as tecnologias mais importantes são desenvolvidas e, não menos relevante, território para onde os lucros são dirigidos. Apenas na década de 1990, a América Latina remeteu um trilhão de dólares das subsidiárias para suas matrizes nos Estados Unidos, conforme dados fornecidos pela Câmara Americana de Comércio.

Mesmo a propalada mobilidade é decidida no "quartel-general". Ademais, os Estados em que as corporações situam seu núcleo atuam vivamente em benefício de suas empresas. Questões como liberdade de repatriação de capitais, desregulamentação do trabalho, leis antigreve e restrições ambientais resultam de pressões e acordos encaminhados por Estados. Do ponto de vista do país que abriga uma seção da corporação, expedientes como renúncia fiscal (que sangram as verbas públicas e representam uma das únicas formas de atrair empresas para as periferias) dependem de política do Estado (nacional e regional).

"Os organismos internacionais assumiram o governo mundial, eclipsando os Estados-nação": no caso dos países periféricos, esses organismos têm um poder extraordinário, ditando, em sintonia com as frações das classes internacionalizadas e em detrimento das esferas públicas, dos governos eleitos e do parlamento local, o fundamental da política econômica, como o câmbio, a constituição de superávits primários, a primazia das exportações, o grau de abertura econômica, as privatizações, a desregulamentação das normas públicas, a flexibilização dos direitos trabalhistas, as grandes orientações da política educacional etc.

Nos países centrais, notadamente na nação imperialista dominante, o quadro é inteiramente outro. As decisões das instituições financeiras internacionais são tomadas por dirigentes nomeados pelos principais Estados imperialistas. O peso de cada nação nesses organismos é proporcional aos recursos por ela depositados. Por isso, o Banco Mundial e o FMI são comandados pelos Estados Unidos, União Européia e Japão. A concessão de créditos a um país periférico depende da decisão dos ministros da Fazenda das nações centrais. A avaliação dos empréstimos obedece, na maior parte das vezes, à lógica política.

Isso explica o empréstimo ao Brasil em 1998, quando o país quebrou às vésperas das eleições e, sem alarde, o FMI e o Banco Mundial emprestaram US\$ 40 bilhões, ou o portentoso empréstimo do Tesouro dos Estados Unidos ao México em 1999.

“Está em curso uma revolução informacional, eliminando fronteiras, fazendo emergir uma nova economia, liderada pelas telecomunicações": Robert Brenner (2003), no magnífico livro O boom e a bolha, comprova que a chamada "revolução informacional", que atraiu centenas de bilhões de dólares 
às bolsas, a rigor não passou de uma bolha que enriqueceu uns poucos e causou uma cadeia de falências. De fato, visto em uma perspectiva mais dilatada no tempo, o crescimento real da produtividade da "nova economia" não foi brilhante. O crescimento da economia americana no período de 1953 a 1973 (velha economia) foi de 2,6\% ao ano, ao passo que entre 1995 e 2000, o auge da bolha, foi de $2,0 \%$.

O que houve foi um movimento especulativo nas bolsas de extraordinária amplitude. Entre 1996 e 2000, as 'teles' “obtiveram US\$ 1,5 trilhão em empréstimos bancários, aos quais adicionaram US $\$ 600$ bilhões em ações emitidas. Com isso, conseguiram, nesse período, aumentar seus investimentos em termos reais a uma taxa média anual de $15 \%$ e acrescentar espetacularmente 331 mil novos empregos" (Brenner, 2003, p. 23). Entretanto, apesar desse vigor nas bolsas, a situação dessas companhias não era nada boa:

\footnotetext{
“Depois de atingir o pico de US\$ 35,2 bilhões em 1996 (ano da desregulamentação do setor), os lucros despencaram para US\$ 6,1 bilhões em 1999 e US\$ 5,5 bilhões negativos em 2000, principalmente quando explodiu o volume de juros da gigantesca dívida dessa indústria. A taxa média de lucro sobre o estoque de capital dessa indústria caiu de uma taxa média de 8,5\%, no período de 1992 a 1996, para 2,4\% em 2000" (Brenner, op. cit., p. 24).
}

O crash e a recessão começariam pelas empresas de internet ("pontocom"), seguindo para os fabricantes de equipamentos e as operadoras de telecomunicações e, depois, para os produtores de componentes destinados à indústria de equipamentos de telecomunicações. O resultado foi o colapso do mercado de ações em 2000, um processo que dura até os dias de hoje: "Em meados de 2002, as ações de telecomunicações perderam 95\% do seu valor, do que resultou o desaparecimento de aproximadamente US\$2,5 trilhões da capitalização do mercado" (Brenner, 2003, p. 25).

Como é possível depreender, falar em "revolução" do setor de comunicação é algo que afronta os fatos. Isso sem falar que grande parte da população mundial não dispõe, ainda, sequer de acesso sistemático à telefonia convencional, que a internet está concentrada nos países da Organização para Cooperação e Desenvolvimento Econômico (OCDE), e que a geração de softwares é quase monopólio de poucas corporações dos Estados Unidos.

"O avanço da globalização fez com que os Estados reduzissem seu tamanho, enfraquecendo sua capacidade de intervenção": no caso dos países do G-7, não há evidências empíricas que corroborem a afirmação. A relação entre o gasto total do governo em relação ao PIB de países que estão no centro da economia mundial em três momentos, 1960, 1980 e 1995, mostra a elevação dos gastos ou a manutenção de altos índices: Alemanha $(34,6 \%$, 48\%, 
$50 \%)$, Estados Unidos $(27 \%, 33 \%, 36 \%)$, Itália $(30 \%, 42 \%, 54 \%)$, Reino Unido $(32 \%, 43 \%, 43 \%)$.

Gastos elevados ou crescentes também são verificados na relação previdência social/PIB em 1980 e 1990: Estados Unidos (14,8\%, 14,6\%), França $(24 \%, 26 \%)$, Itália $(20 \%, 24,5 \%)$, Reino Unido $(21 \%, 22 \%)$. Apenas na Alemanha houve redução expressiva: de $36 \%$ para $23 \%$. No entanto, mais do que os indicadores, a própria forma de atuação dos Estados dos países centrais comprova que o capitalismo requer Estados robustecidos. Na grave crise do México, em 1994, o presidente Clinton injetou US\$ 20 bilhões para preservar a governabilidade econômica e política deste país, com o objetivo de resguardar as empresas dos Estados Unidos.

As mesmas motivações levaram os Estados Unidos a apoiar os empréstimos do FMI nas crises asiática e brasileira de 1998. Mais do que nunca, as corporações multinacionais necessitam da intervenção estatal para manter o ambiente propício aos negócios. São os Estados que formam os blocos econômicos que definem politicamente as tarifas alfandegárias e as cotas (automóveis, calçados, suco de laranja, aço). Na conquista de mercados, agem por meio de subsídios diretos e indiretos. A propalada produtividade da agricultura dos Estados Unidos não seria a mesma sem os vultosos subsídios para a água e a energia, por exemplo.

Já os países periféricos, quando recebem "ajuda" das instituições financeiras internacionais, são forçados a abrir seus mercados. As recentes "negociações" para a formação da ALCA reforçam a proposição de que os Estados desempenham papel chave no capitalismo de hoje. É preciso considerar, ainda, a ação político-militar da principal nação imperialista na sustentação dos interesses do capital: a desestabilização do governo na Venezuela e a guerra do Iraque são ações movidas pelo interesse no controle da energia fóssil.

Discutindo o papel do Estado nos países centrais, Borón (2003) oferece uma consistente síntese contra a tese de que está em marcha um Estado-mínimo, conforme a propaganda neoliberal:

“O capitalismo contemporâneo promove uma cruzada teórica em oposição ao estado, enquanto no plano prático não cessa de fortalecê-lo e indicar-lhe novas tarefas e funções. Na realidade, a "ilusão estatal" pareceria melhor situada naquelas concepções que, em que pese as evidências em contrário, não chegam a distinguir a retórica anti-estadista da prática estatizante do capitalismo "realmente existente", nem a perceber o caráter cada vez mais estratégico que o estado tem assumido para garantir a continuidade da dominação burguesa" (Bóron, 2003, p. 16). 


\section{Estado e Educação}

Certas obrigações do Estado com o ensino fundamental, em especial para as populações "pobres", são aceitáveis na ótica neoliberal. São conhecidas as preocupações do Banco Mundial com a governabilidade (segurança) e a crença deste organismo na contribuição educacional para "aliviar" a pobreza e promover a contenção social (Leher, 1999). Mas, no caso do ensino superior, o quadro é outro. Desde a Rodada Uruguai do GATT, o setor de serviços foi inserido nos tratados de livre comércio.

Nesse processo, temas cruciais como propriedade intelectual e patentes se transformaram em objeto de regulamentação pelos Estados a partir de violenta pressão do Departamento de Estado norte-americano. No caso brasileiro, as injunções para a aprovação de uma lei que, conforme o então Senador Severo Gomes, chegou ao conhecimento do parlamento ainda em inglês, foram abertas, conforme noticiou a imprensa da época (19901996).

Com a Rodada Uruguai, todo o esforço do Movimento dos Países Nãoalinhados para assegurar o domínio das tecnologias estratégicas, conforme a manifestação da Conferência de Bandung, foi por terra. O drama dos países da África subsaariana em relação aos custos dos medicamentos que compõem o chamado "coquetel" para Aids colocou em evidência mundial o significado das patentes. Em alguns casos, a propriedade intelectual representa $90 \%$ do custo final do medicamento. Assim, conforme a Organização Mundial da Saúde (OMS), a expectativa de vida dessas populações em 2010 poderá ser de apenas 39 anos, apesar de a ciência já dispor de conhecimento para debelar os efeitos da doença.

Estabelecido que o conhecimento científico, o conhecimento tecnológico de caráter científico e as principais inovações são mercadorias protegidas pelas normas da OMC, a próxima etapa no avanço da institucionalização do apartheid educacional planetário é a abertura do mercado educacional do ensino superior, tout court. De fato, os Estados Unidos encaminharam uma solicitação formal à OMC nesse sentido e reivindicam a completa liberalização do setor, inclusive para cursos à distância.

Um breve levantamento das políticas de Estado para a educação na América Latina atesta que os diversos países da região assimilaram as diretrizes do Banco Mundial de que, doravante, a preocupação deve ser com as "primeiras letras", isto é, com a alfabetização instrumental. À primeira vista, um objetivo louvável, porém, quando a questão é examinada mais amplamente, sobressai o caráter conservador e neocolonial dessas políticas. $\mathrm{O}$ hiato que separa as nações centrais das periféricas na produção do conhecimento já é abissal. Atualmente, dos 3,5 milhões de patentes existentes, apenas $1 \%$ está registrada nos países periféricos. 
Caso a política de "desmonte" do aparato de C\&T construído no período da modernização excludente tenha continuidade, é de se esperar que a dependência nas áreas de saúde, agricultura, energia, educação e transporte agrave substancialmente a qualidade de vida dos povos. Obviamente, o modelo criado no governo militar não serve de referência. O patrimônio construído somente pode ser reivindicado, embora com críticas, porque pesquisadores, estudantes e corpo funcional dos centros de pesquisa e das universidades alargaram os objetivos dessas instituições muito além dos limites previstos pelo governo militar, consolidando áreas estratégicas e de interesse público.

A tendência ao desmantelamento completo do aparato de C\&T pode ser agravada e acelerada se a ALCA vier a ser aprovada. Uma das cláusulas do acordo prevê que as compras governamentais terão de obedecer à concorrência dentro da área de livre comércio. Assim, quando uma campanha de vacinação for realizada, o governo terá de optar entre a Fiocruz, por exemplo, e uma grande corporação, que, provavelmente, utilizará dumping para vencer a "concorrência". Qual será o futuro da produção de fármacos e de vacinas no país?

Em suma, toda a política de reforma das atribuições do Estado na área educacional contribui para a mercantilização da educação. E o pior: em função da condição capitalista dependente, as assimetrias entre centro e periferias deformarão de modo incorrigível o perfil das universidades e dos centros de pesquisa (pelo menos em uma escala de tempo contada em termos geracionais), transformando-os em centros de ensino e locais de adequação de pacotes tecnológicos obsoletos. Com isso, o Estado será moldado de modo que a mesma política do Império seja restabelecida quase dois séculos mais tarde: ao povo, bastam as primeiras letras.

\section{Demarcar o público e o privado, contra a mercantilização dos direitos sociais}

As recentes reformas do Estado valem-se de um léxico em que os termoschave guardam forte proximidade com o liberalismo, como: 'sociedade civil', 'indivíduo', 'liberdade', 'segurança', 'competição', 'mercadoria' e 'cidadania', entre outros. Este léxico foi adaptado pelo neoliberalismo para responder aos novos desafios do capital, fazendo uso reiterado de verbos como: 'liberalizar', 'desregulamentar', 'flexibilizar', 'descentralizar' e 'autonomizar'. Novas expressões foram criadas — 'terceiro setor', 'organizações não-governamentais', 'empregabilidade', 'produtivismo' - enquanto outras foram ressignificadas: 'eficiência', 'publicização' etc.

É forçoso reconhecer que muitas dessas expressões fazem parte do vocabulário de membros de setores da esquerda outrora na oposição à ditadu- 
ra empresarial-militar e hoje dirigentes de ONGs ou de instâncias do Estado, pessoas que apregoam a necessidade de 'liberalizar' estas mesmas instâncias.

A verificação de afinidades entre esses discursos é relevante para esse debate. Sader (2003), preocupado com questões relacionadas a este estudo, aponta a afinidade dos discursos que opõem o privado ao Estatal, no lugar da oposição clássica público/privado. A sua proposição é de que a oposição público/privado foi deslocada para Estatal/privado. Assim, a crítica ao "estatismo" teve como contraponto o "mercado", lugar da eficiência, do mérito, da criatividade, da iniciativa e da criação. Os novos termos em oposição favoreceram os neoliberais, pois permitiram a desqualificação do Estado e o desaparecimento do "público".

Com efeito, o pensamento político e jurídico moderno se fundamenta na distinção Público x Privado. Neste escopo, a distinção entre o que é público e o que é privado possui clara nitidez (privado = não-público). Determina-se o interesse público pelo contraste com o interesse privado e vice-versa. É a oposição entre o que é coletivo, universal, geral e o que é individual, grupal, particularista. Nas ciências sociais, significa a oposição entre a "sociedade de iguais" e a "sociedade de desiguais", entre política (interesse geral) e economia (interesse mercantil) ou, nos termos de Marx, entre "o céu da política" e o "inferno das relações de trabalho" (Sader, 2003).

Essa operação ideológica foi urdida por meio de uma hábil teorização da "transição democrática", notadamente por brasilianistas como Stepan e, localmente, por Fernando Henrique Cardoso (Leher, 2002; Sader, 2003). A teoria do autoritarismo possibilitou a grande operação ideológica de centralização do campo teórico na polarização estatal/privado, deslocando o público. Desse modo, os termos em antípoda passaram a ser Estatal-autoritário x Privado-democrático. A democracia deveria ser buscada na sociedade civil. Não importa que empresários tenham sustentado e se beneficiado da ditadura.

A partir da "transição lenta, gradual e segura", um pólo foi definido como "os adeptos da democracia e da supremacia da esfera privada"; o outro, como "os adeptos do estatismo e do autoritarismo", uma oposição que permitiu que a direção da transição contasse com a participação dos principais apoiadores da ditadura, convertidos em anti-autoritários e membros da sociedade civil democrática.

Com o êxito dessa formulação, o discurso anti-estatal foi largamente utilizado para esconder objetivos não-públicos das políticas neoliberais. O ápice desse deslocamento foi o Plano Diretor da Reforma do Estado, em que entidades não-públicas, como as organizações sociais de direito privado, estabeleceriam contratos de gestão com o Estado, na lógica dos serviços competitivos. Como faltam a essas organizações os principais requisitos da esfera pública - a universalidade, a igualdade, os interesses gerais, a lei e os ob- 
jetivos emancipatórios —, a Reforma pode ser considerada inequivocamente privatizante.

Um objetivo político crucial, em especial no Brasil, visto a manifestação popular por uma política alternativa ao neoliberalismo, expressa no processo eleitoral de 2002, é colocar os debates em seus devidos termos, restabelecendo a oposição entre público e privado. O Estado, na perspectiva marxiana, tem de ser compreendido como totalidade contraditória, locus de contradições e oposições entre classes, em que, através de mediações produzidas nas lutas de classes, o espaço público pode ser ampliado.

Este não é um processo exclusivamente cultural ou que se esgota no terreno do pensamento, mas um movimento de lutas, confrontos (inclusive com o aparato repressivo próprio do Estado) e ações massivas, capazes de colocar em questão a divisão capitalista do trabalho e a própria propriedade privada (politização da esfera econômica). As ações do MST, por exemplo, podem ser inscritas nesse escopo, assim como as greves de servidores contra os pilares da reforma do Estado e as manifestações que fortalecem a democracia real e a construção da hegemonia dos subalternos.

Borón (2003, p. 18) também sustenta que a negação da ordem capitalista atual, condensada nos Estados, não poderá ser feita sem grandes confrontos. A passagem para uma outra sociedade, seja socialista ou libertária, com base em estratégias que se recusam a enfrentar o problema do poder de Estado é pueril:

“Dizemos quiméricos porque se estabelece um objetivo grandioso sem se ater às suas mediações históricas necessárias e no fato de que antes de alcançá-lo é imprescindível passar pelo purgatório de um longo, complexo e turbulento processo de transição, no qual as forças da velha ordem lutarão uma batalha desesperada, apelando a todos os meios disponíveis, igualmente violentos e 'pacíficos', para impedir a realização da utopia. E aqui cabe lembrar o que Marx e Engels disseram n'O Manifesto Comunista e em tantas outras passagens de sua obra: que o problema com o comunismo utópico não estava nos belos mundos imaginados por seus pensadores e sim no fato de que aqueles não surgiam de uma análise científica das contradições da sociedade capitalista, nem da identificação dos atores concretos que haveriam de assumir a tarefa de construí-los, assim como tampouco delineavam o itinerário histórico que seria preciso percorrer antes de chegar ao destino" (Bóron, 2003, p. 18).

A despeito das importantes considerações sobre a relação entre sociedade civil e Estado na obra de Gramsci, em particular nos Cadernos, quando examina as diferenças entre o Oriente (Rússia) e o Ocidente (Europa Ocidental) e que o levam a afirmar a supremacia da sociedade civil (persuasão, consentimento) sobre o Estado (coerção), é preciso destacar que os funda- 
mentos do Estado Ocidental já contêm as instituições cujo objetivo central é assegurar o domínio das classes capitalistas, como, por exemplo, o Parlamento. Assim, o Estado burguês somente representa o interesse geral de forma aparente, o que não quer dizer que as conquistas dos trabalhadores, expressas através de políticas públicas, não sejam concretas e relevantes. Perry Anderson produziu uma sofisticada elaboração a esse respeito:

“O Estado burguês, por definição, 'representa' a totalidade da população, abstraída de sua divisão em classes sociais, como cidadãos individuais e iguais. Em outras palavras, ele apresenta os homens e mulheres em posições desiguais na sociedade civil como se elas fossem iguais perante o Estado. O parlamento (...) reflete a unidade fictícia da nação perante as massas, como se ele fosse o próprio governo delas. A existência do estado parlamentar constitui o quadro formal de todos os outros mecanismos ideológicos da classe dirigente. Ela fornece o quadro geral em que cada mensagem específica é transmitida em qualquer outro lugar. Esse código é tão poderoso porque os direitos jurídicos da cidadania não são uma simples miragem: pelo contrário, as liberdades civis e o sufrágio da democracia burguesa são uma realidade tangível, cuja realização foi em parte obra do próprio movimento operário e cuja perda seria uma derrota importante para a classe operária" (Anderson, 2002, p. 41).

Para ampliar os direitos civis (esfera pública) é preciso distinguir, na sociedade civil, os interesses das classes. Os dominantes tentam ocultar o fato de que os organismos privados podem expressar interesses particularistas. Marx, em A crítica ao programa de Gotha, compreendeu que o Estado enreda, controla, regula, supervisiona e mantém sob tutela a sociedade civil, desde suas manifestações de existência, as mais vastas, até seus movimentos mais insignificantes, desde seus modos de existência mais gerais até a vida privada dos indivíduos.

Somente os interessados no fim das classes - e que, portanto, têm como objetivo a extinção do Estado capitalista - podem criar um "Estado ético" ou um "organismo social unitário técnico-moral", no sentido gramsciano do termo. Historicamente, são os movimentos sociais autônomos em relação aos governos, credos e seitas religiosas que podem operar as contradições Estado-público-privado e conduzi-las de modo a fazer com que o Estado seja, de fato, uma esfera pública. 


\section{Notas}

1 Professor Adjunto da Faculdade de Educação da UFRJ, Doutor em Educação (USP), pesquisador sênior do Conselho Latino Americano de Ciências Sociais. Desenvolve pesquisa no Laboratório de Políticas Públicas da UERJ. Ex-presidente do Sindicato Nacional dos Docentes das Instituições de Ensino Superior (ANDES - SN) (2000-2002). <rleher@ uol.com.br>

2 Hegemonia, Fragilidade Democrática e Resistência Social na Nova Ordem Mundial. In: Seminário pós-neoliberalismo-3, LPP/UERJ, 22/10/02.

\section{Referências}

ANDERSON, Perry. 2002. Afinidades seletivas. São Paulo: Boitempo Editorial.

ARRIGHI, Giovanni. 1997. A ilusão do desenvolvimento. Petrópolis, RJ: Vozes.

BELLUZO, Luiz G. M. 2002. Prefácio. In: Desenvolvimento em crise: a economia brasileira no último quarto do século $X X$ (Carneiro, Ricardo). São Paulo: Editora UNESP, IE - Unicamp.

BOLTANSKI, Luc; CHIAPELLO, Éve. 1999. Le nouvel esprit du capitalisme. Paris: Gallimard.

BORÓN, Atílio. 2003. Poder, "contrapoder"y "antipoder". Notas sobre un extravio teórico político en el pensamiento crítico contemporáneo. CLACSO (Mimeo).

BRENNER, Robert. 2003. O boom e a bolha: os Estados Unidos na economia mundial. Rio de Janeiro: Record.

BRESSER PEREIRA, Luiz Carlos 1996. Crise econômica e reforma do Estado no Brasil - para uma nova interpretação da América Latina. São Paulo: Editora 34.

CARNEIRO, Ricardo. 2002. Desenvolvimento em crise: a economia brasileira no último quarto do século $X X$. São Paulo: Editora Unesp, IE - Unicamp.

CASTORIADIS, Cornelius. 1983. La logique des magmas et la question de l'autonomie. In: L'auto-organisation. (Dumouchel, P.; Dupuy, J-P, orgs.), pp. 421-423, Paris: Éditions du Seuil.
CECEÑA, Ana Esther; SADER, Emir. (org.) 2002. A guerra infinita: hegemonia e terror mundial. Petrópolis, RJ: Vozes; Rio de Janeiro: LPP; Buenos Aires: CLACSO.

CHESNAIS, François. 1996. A mundialização do capital. São Paulo: Xamã.

DUPUY, Jean-Pierre. 1983. L'auto-organisation du social dans la pensée libérale et économique. In: L'auto-organisation: de la physique au politique (Dumouchel, P.; Dupuy, J-P., orgs.). Paris: Éditions du Seuil.

FERNANDES, Florestan. 1977. Circuito fechado: quatro ensaios sobre o "poder institucional". 2a. ed. São Paulo: Hucitec.

LA JORNADA, 2003. Sahagún y Gordillo sellan alianza entre Vamos Mexico y el SNTE. La Jornada, 3 fev. C-2.

LEHER, Roberto. 1999. Um novo senhor da educação? A política educacional do Banco Mundial para a periferia do capitalismo. Outubro, 3:19-30.

.2000. Tempo, autonomia, sociedade civil e esfera pública: uma introdução ao debate a propósito dos novos movimentos sociais na educação. In: $A$ cidadania negada - Políticas de exclusão na educação e no trabalho (Gentili, Pablo; Frigotto, Gaudêncio, orgs.), pp. 145-176, Buenos Aires: CLACSO.

2002. Movimentos sociais, democracia e educação. In: Democracia e construção 
do público no pensamento educacional brasileiro (Fávero, O.; Semeraro, G. orgs.), pp. 187-211, Petrópolis, RJ: Vozes.

LIMOEIRO-CARDOSO, Miriam. 1999. Ideologia da globalização e (des)caminhos da ciência social. In: Globalização excludente - desigualdade, exclusão e democracia na nova ordem mundial (Gentili, Pablo, org.), pp. 96-127, Petrópolis, RJ: Vozes.

MARX, Karl. 1985. Crítica ao programa de Gotha. In: Obras escolhidas. (Marx, K.; Engels, F.) Lisboa: Ed. Avante!; Moscovo: Ed. Progresso.

MÉSZAROS, István. 2003. O século XXI: socialismo ou barbárie? São Paulo: Boitempo Editorial.

NASSIF, Luís. 2003. O mapa do buraco externo. Folha de São Paulo.19 de fev. B-3.

OHMAE, Kenichi. 1999. O fim do Estadonação. Rio de Janeiro: Campus; São Paulo: Publifolha.
SADER, Emir. 2002. A new landscape of the left. New Left Review, 17:87-99. 2003. O público, o estatal e o privado. Projeto de pesquisa para renovação de bolsa de produtividade do CNPq.

SECOD (Secretaria Especial do Conselho de Desenvolvimento Econômico e Social da Presidência da República). 2003. Termo de Referência para a Formação da Secretaria Especial do Conselho de Desenvolvimento Econômico e Social da Presidência da República (SECOD) e do seu Conselho de Desenvolvimento Econômico e Social (CODES). Brasília.

SILVA JR., João dos Reis; SGUISSARDI, Valdemar. 1999. Novas faces da educação superior no Brasil - Reforma do Estado e mudança na produção. Bragança Paulista: Edusf. 